\title{
Reduced neonatal mortality in a regional hospital in Mozambique linked to a Quality Improvement intervention
}

\author{
Maria Elena Cavicchiolo ${ }^{1,3^{*}} \mathbb{D}$, Paolo Lanzoni ${ }^{1}$, Mazungo Olivier Wingi ${ }^{2}$, Damiano Pizzol ${ }^{1}$, Marco Daverio ${ }^{3}$,
} Liviana Da Dalt ${ }^{3}$, Giovanni Putoto ${ }^{1}$ and Daniele Trevisanuto ${ }^{3}$

\begin{abstract}
Background: Neonatal mortality remains a serious health issue especially in low resource countries, where 99\% of neonatal deaths occur. Doctors with Africa CUAMM is an Italian non-governmental organization in the field of healthcare that has been working in Africa since 1955. In Mozambique, at the Central Beira Hospital (CBH), it has a project with the aim of supporting the neonatal intensive care unit (NICU) and the Obstetrical Department of the CBH through a multi-level intervention. Our aim was to evaluate the effectiveness of CUAMM continuous Quality Improvement intervention in terms of reduction of the overall neonatal mortality rate in the NICU of CBH.

Methods: A baseline analysis was performed in order to assess the actual standard of neonatal care. Subsequently, the intervention was focused on three main areas: infrastructure, equipment and clinical protocols improvement. A retrospective pre- (2013)/post- (2014) implementation analysis of clinical outcomes was performed.

Results: Total population included 4,276 newborns, 2,118 (50\%) born in 2013 and 2158 (50\%) born after implementation. Baseline characteristics of the two groups were similar apart from a higher incidence of outborn neonates (33\% vs $30 \%, p=0.02)$ and a lower incidence of Apgar score $<7$ at $5 \mathrm{~min}(37 \%$ vs $43 \%, p<0.01)$. The rates of admissions for asphyxia (22\% vs 30\%), sepsis (4\% vs $7 \%$ ) and prematurity (18\% vs $28 \%$ ) increased between the two study period. Mortality rate for each of these causes decreased from before to after the implementation: asphyxia (34\% vs 19\%, $p<0.01)$, sepsis (39\% vs $28 \%, p=0.06)$ and prematurity ( $43 \%$ vs $33 \%, p<0.01)$.

Conclusion: We found a reduction in mortality rate among newborns admitted to CBH's NICU after the first year of CUAMM intervention. Most of this reduction can be attributed to the decrease in deaths for asphyxia, sepsis and prematurity. A Quality Improvement intervention based on infrastructural, equipment and clinical objectives was associated with a reduction of neonatal mortality rate in a low-resource NICU.
\end{abstract}

Keywords: Neonatal mortality, Low resource setting, Quality improvement, NGO

\section{Background}

In the last two decades, the global "under-five mortality" has dropped from 90 deaths per 1,000 live births in 1990 to 46 in 2013 [1]. Despite these gains in the under-five mortality, the proportion of deaths that occurs within the first month of life (the neonatal period) has increased from $37 \%$ in 1990 to $44 \%$ in 2013, showing that declines

\footnotetext{
* Correspondence: mecavicchiolo@gmail.com

'Doctors with Africa CUAMM, Padova, Italy

${ }^{3}$ Department of Woman's and Child's Health, University of Padova, Via

Giustiniani 3, Padova 35128, Italy

Full list of author information is available at the end of the article
}

in neonatal mortality rate is slower than for older children $[1,2]$. Neonatal mortality remains a big issue particularly in poor resource countries, where poverty is strongly associated with mortality rate and $99 \%$ of the neonatal deaths occurs [2, 3]. Worldwide the main causes of neonatal death are: prematurity (28\%), infections $(26 \%)$, and intrapartum related events (23\%) [4].

Mozambique, as the other sub-Saharan African countries, has an extremely high neonatal mortality rate. In 2012, neonatal mortality rate in Mozambique was estimated at 34/1000 live births. The rate of stillbirth was $28 / 1000$ 
total births. Neonatal deaths constituted 35\% of an estimated 85000 deaths under five years of age [4].

Doctors with Africa CUAMM is an Italian nongovernmental organization operating in the field of healthcare [5]. It has been working in Africa since 1955 for the promotion of African population's health. In Mozambique since 1978, CUAMM is now collaborating with the Obstetrical Department and with the Neonatal Intensive Care Unit (NICU) of the Central Beira Hospital $(\mathrm{CBH})$ : the second largest city in the country. This project, focused on Child's and Mother's Health, started in January 2014 with the aim of supporting the NICU and the Obstetrical Department of the CBH through a multilevel intervention including renovation of the wards, equipment provision and education of the local staff.

The aim of the present study was to assess the effectiveness of CUAMM interventions in the $\mathrm{CBH}$ in terms of reduction of the neonatal mortality rate through a retrospective analysis of the pre- and post-implementation data.

\section{Methods}

\section{Setting and population}

The city of Beira has about 500,000 inhabitants, of which $17 \%$ have less than 5 years. $\mathrm{CBH}$ is a 733 -bed government tertiary referring and teaching Hospital for the central region of the Country (population of about 7 million) in Mozambique and the second hospital of the country [6].

At the Obstetrical Department about 5,300 deliveries occur every year ( $24 \%$ of the deliveries expected for the total population), $29 \%$ of which are caesarean sections, with a maternal mortality ratio of 520 per 100,000 live births [5]. All the women who delived in the $\mathrm{CBH}$ received at least one prenatal visit; no one received antenatal corticosteroids.

The maternal ward is staffed by 13 midwives who have the full responsibility of neonatal management at birth. In all delivery rooms as well as operating rooms, an infant warmer and an emergency neonatal set, including a self-inflating bag, face-masks, suction device and ties, are available.

Criteria for admission to the CBH's NICU are inborn and outborn patients of all gestational ages up to a postnatal age of 7 days. Before CUAMM intervention, the staff was composed by two nurses, three medical residents and one neonatologist during the morning time till 2.00 p.m. and only one nurse during the rest of the day.

It was a 30-bed unit with about 2,500 admissions per year, $30 \%$ of which were outborn [5]. The ward was divided into 3 rooms: one intensive care unit, one for premature babies, and one for post intensive care. Electricity was provided $24 \mathrm{~h}$ a day but in case of black out there wasn't a system of emergency generator. The Kangaroo Mother Care (KMC) was performed in a separated 9-bed room. The NICU was an 8-bed room, provided of a system of non-invasive ventilation (bubble nCPAP), without monitors. Intravenous fluids and first line medications (i.e. antibiotics) were available. The NICU had space heaters to achieve a goal room temperature of $25{ }^{\circ} \mathrm{C}$. A water purification system was not available.

\section{Baseline survey and interventions}

When CUAMM started its support in the CBH in January 2014, baseline data were collected in order to establish the strengths and the weaknesses of the actual care. A multidisciplinary working group composed by the local staff and the Chief of the Pediatric Department identified the strategies for the improvement of the standard of care in the Hospital's NICU.

The interventions were focused on improving three orders of areas: infrastructure, equipment and clinical protocols. Comprehensive assessments of the quality of care follow the classical Donabedian approach encompassing measures of structure, process and outcome was used (Table 1) [7].

The study compared patients admitted to NICU in the pre-intervention phase $\left(1^{\text {st }} \mathrm{Jan}-31^{\text {th }}\right.$ Dec, 2013) to the newborns admitted during the first year of CUAMM presence $\left(1^{\text {st }} J a n-31^{\text {th }}\right.$ Dec, 2014).

\section{Definitions}

Prematurity: a newborn weight less than 2,500 g and a maternal fundal height less than $34 \mathrm{~cm}$ at the moment of the delivery;

Asphyxia: it was a clinical diagnosis based on the $5 \mathrm{~min}$ Apgar score lower than 7 and/or Sarnat \& Sarnat score $\geq 2$ at NICU admission; [8]

Sepsis: it was a clinical diagnosis based on neurologic examination, detection of moderate hypothermia $\left(<36{ }^{\circ} \mathrm{C}\right)$ or hyperthermia $\left(>37.5^{\circ} \mathrm{C}\right)$, respiratory distress (tachypnea, chest wall retractions, expiratory grunting, nasal flaring and cyanosis) and breastfeeding difficulties;

Low birth weight (LBW): patients with a birth weight less than 2,500 g at birth;

Very low birth weight (VLBW): patients with a birth weight less than $1,500 \mathrm{~g}$ at birth.

\section{Data collection}

Data extraction was performed by a trained external member (not involved in clinical activity nor in the study design) by using a piloted clinical report form in order to ensure consistent data collection. Chart abstraction was performed in accordance with previously published guidelines [9]. The abstractor was not blinded to the study question. Data were collected by reviewing all the original medical records as well as the clinical electronic databases. 
Table 1 Quality Improvement interventions classified according to the Donabedian framework

\begin{tabular}{|c|c|c|c|}
\hline Structures & & Process & Outcomes \\
\hline \multirow[t]{3}{*}{ Structural } & Lack of space dedicated to the KMC & $\begin{array}{l}\text { Creation of two new rooms with six extra beds for KMC, } \\
\text { for a total of fifteen beds }\end{array}$ & \multirow{18}{*}{$\begin{array}{l}\text { Reduction of neonatal } \\
\text { mortality due to asphyxia, } \\
\text { prematurity and sepsis }\end{array}$} \\
\hline & No bathroom for the mothers & $\begin{array}{l}\text { Rehabilitation of one bathroom for the patients and one } \\
\text { for the NICU staff }\end{array}$ & \\
\hline & No mosquito nets on beds & $\begin{array}{l}\text { Painting walls, repairing windows and installation of } \\
\text { impregnated mosquito nets for each KMC bed }\end{array}$ & \\
\hline \multirow[t]{5}{*}{ Equipment } & Lack of equipment and supplies & $\begin{array}{l}\text { Oxygen concentrators with implementation of pulse } \\
\text { oximeter utilization and technical maintenance }\end{array}$ & \\
\hline & & $\begin{array}{l}\text { Glucometer and point-of-care testing for C-Reactive } \\
\text { Protein and technical maintenance }\end{array}$ & \\
\hline & & UVB light for phototherapy and technical maintenance & \\
\hline & & Infusion pumps and technical maintenance & \\
\hline & & First and second line antibiotics & \\
\hline \multirow[t]{10}{*}{ Clinical } & $\begin{array}{l}\text { Lack of standardization of the quality } \\
\text { of work between different doctors }\end{array}$ & $\begin{array}{l}\text { Creation of diagnostic-therapeutic protocols for the main } \\
\text { neonatal diseases (sepsis, dyspnea, prematurity, asphyxia, } \\
\text { hypoglycemia, neonatal seizures, enteral feeding) }\end{array}$ & \\
\hline & Lack of internal organization & $\begin{array}{l}\text { Monthly meeting with doctors working in the NICU focused } \\
\text { on good clinical practice, discussion of case reports, medical } \\
\text { issues and protocols }\end{array}$ & \\
\hline & & $\begin{array}{l}\text { Scheduled visiting hours, ward access permitted only to } \\
\text { internal personnel and families }\end{array}$ & \\
\hline & & Organized staff shifts & \\
\hline & & $\begin{array}{l}\text { Payment of an extra shift performed by a nurse during the } \\
\text { afternoon and night to obtain a nurse/patient ratio of } \\
1 / 15 \text { compared to } 1 / 30 \text { of the pre-intervention }\end{array}$ & \\
\hline & Lack of basic hygienic rules & $\begin{array}{l}\text { Meeting twice a month with nurses and NICU's staff on hand } \\
\text { washing, cup feeding, newborn cleaning, water purification } \\
\text { for hand washing and formula milk preparation }\end{array}$ & \\
\hline & $\begin{array}{l}\text { Lack of theoretical knowledge and } \\
\text { technical skills about the neonatal } \\
\text { resuscitation in the delivery room }\end{array}$ & $\begin{array}{l}\text { Organization of a neonatal resuscitation course for the } \\
\text { midwives on January } 2014 \text { with a Portuguese-speaking } \\
\text { certified neonatologist midwives }\end{array}$ & \\
\hline & & On-the-job training by a certified local midwife a week per month & \\
\hline & & $\begin{array}{l}\text { Weekly meeting with the midwives with discussion of one } \\
\text { clinical case }\end{array}$ & \\
\hline & & $\begin{array}{l}\text { Installation of a camera in the delivery room and in the } \\
\text { operating room to record } 24 / 7 \text { the neonatal resuscitation } \\
\text { made by the midwives working in the Obstetrical Department } \\
\text { to evaluate their performances }\end{array}$ & \\
\hline
\end{tabular}

\section{Statistical analysis}

Descriptive statistics were used to compare baseline characteristics of the study groups. A bivariate analysis was performed to evaluate the differences observed between the pre- and post- intervention population. For binary variables the chi-square test was used. A $p$-value $<0.05$ was considered statistically significant. All data were analysed with SPSS 17.0 for Windows (IBM SPSS Statistics, IBM Corporation, Chicago, IL).

\section{Results}

During the study period, 4,276 patients were admitted to the NICU, 2,118 (50\%) in the pre-intervention phase and $2,158(50 \%)$ during the first year of CUAMM presence.
The baseline characteristics of the two groups were similar apart from incidence of outborn neonates $(30 \%$ vs $33 \%, p=0.02$ ), incidence of Apgar score $<7$ at $5 \mathrm{~min}$ (43\% vs $37 \%, p<0.01$ ), and number of VLBW (5\% vs. $4 \%, p=0.02$ ) (Table 2).

Table 3 summarizes the admissions and the deaths in relation to the diagnosis of the patients during the two study periods. Overall neonatal mortality rate decreased from 26 to $18 \%(p<0.01)$ after the CUAMM intervention; no differences were noted in mortality rate of outborn infants during the 2 study periods. Despite the significant higher rate of admissions for asphyxia (22\% vs $30 \%$ ), sepsis ( $4 \%$ vs $7 \%$ ) and prematurity (18\% vs $28 \%$ ), the mortality rate for each of these causes decreased: asphyxia (34\% vs $19 \%, p<0.01)$, 
Table 2 Demographic and clinical characteristics of patients admitted to the NICU pre- versus post- CUAMM interventions

\begin{tabular}{llll}
\hline & $\begin{array}{l}\text { Pre- } \\
\text { intervention } \\
n=2118\end{array}$ & $\begin{array}{l}\text { Post- } \\
\text { intervention } \\
n=2158\end{array}$ & $p$ \\
\hline Male gender, $\mathrm{n}(\%)$ & $1102(52)$ & $1187(55)$ & 0.05 \\
Outborn babies, $\mathrm{n}(\%)$ & $635(30)$ & $715(33)$ & 0.02 \\
Caesarean sections, $\mathrm{n}(\%)$ & $614(29)$ & $627(29)$ & 0.96 \\
5-min Apgar score < 7, n (\%) & $911(43)$ & $801(37)$ & $<0.01$ \\
Birth weight 1,500-2,499 g, n (\%) & $349(16)$ & $357(17)$ & 0.95 \\
Birth weight 1,000-1,499 g, n (\%) & $104(5)$ & $77(4)$ & 0.02 \\
\hline
\end{tabular}

sepsis $(39 \%$ vs $28 \%, p=0.06)$ and prematurity (43\% vs $33 \%, p<0.01)$.

\section{Discussion}

This study shows a reduction in mortality rate among infants admitted in the CBH's NICU after CUAMM intervention. Most of this success can be attributed to prematurity and asphyxia reduction.

Preterm infants are rising globally, both in high as well as low income countries [4]. A complex approach including thermal control, respiratory support, infection prevention and optimization of fluid/caloric intake is indicated in these vulnerable patients. Besides to these interventions, we implemented the $\mathrm{KMC}$ approach at the $\mathrm{CBH}$.

Improved overall survival of premature infants in poor resource settings is, among the others, due to the introduction of KMC approach [10]. The KMC is an evidence-based approach that has been demonstrated to reduce mortality and morbidity in preterm infants in poor resources countries. Several meta-analysis show that KMC significantly reduces preterm mortality and improves other outcomes including sepsis, emotional

Table 3 Admissions and deaths in relation to the diagnosis of all patients admitted to the NICU (pre- versus post- CUAMM intervention)

\begin{tabular}{llll}
\hline & $\begin{array}{l}\text { Pre- } \\
\text { intervention } \\
n=2118\end{array}$ & $\begin{array}{l}\text { Post- } \\
\text { intervention } \\
n=2158\end{array}$ & $p$ \\
\hline$N^{\circ}$ of deaths, n (\%) & $544(26)$ & $396(18)$ & $<0.01$ \\
Total & $274(50)$ & $199(50)$ & 0.97 \\
Outborn patients & $492(20)$ & $641(30)$ & $<0.01$ \\
Admission for asphyxia, n (\%) & $168(34)$ & $122(19)$ & $<0.01$ \\
Deaths for asphyxia, n (\%) & $111(4)$ & $158(7)$ & $<0.01$ \\
Admission for sepsis, n (\%) & $43(39)$ & $44(28)$ & 0.06 \\
Deaths for sepsis, n (\%) & $447(18)$ & $605(28)$ & $<0.01$ \\
Admission for prematurity, n (\%) & $192(43)$ & $200(33)$ & $<0.01$ \\
Deaths for prematurity, n (\%) & 192 & &
\end{tabular}

attachment in mothers, and weight gain when compared to conventional care in preterm infants [10-13].

The implementation of this evidence-based method in the CBH's NICU could explain, at least partly, the reduction in neonatal mortality rate due to prematurity.

Between $5-10 \%$ of all babies born in facilities need some degree of resuscitation, such as tactile stimulation or airway clearing or positioning and approximately 3-6\% require basic neonatal resuscitation, consisting of simple initial steps and assisted ventilation $[14,15]$. These procedures can reduce intrapartum-related neonatal deaths by $30 \%$ [16]. In many developing countries, an inability to offer effective newborn resuscitation has been tolerated for many years, reflecting the belief that resuscitation is complex and dependent on the presence of expensive technology impossible to apply in low-income health systems [14]. In 2006, Newton and English wrote a systematic review demonstrating that is possible to provide resuscitation with simple equipment and minimal skills, without compromising the quality of the intervention [17]. In the last decade in more than 70 poor incoming countries newborn resuscitation programs, designed to teach basic knowledge and skill in under resources settings, have been performed with good results in terms of reduction of mortality and morbidity for neonatal asphyxia [18-20].

Based on this evidence, in January 2014, CUAMM organized a neonatal resuscitation course to the midwives of the $\mathrm{CBH}$. Before and after the course the intervention on the newborn needing resuscitation were video recording and analyzed by an expert neonatologist in Italy. These videos showed an improvement on the quality of the resuscitations [21]. In addition to the course, the educational program included the training of a local midwife responsible of a continuous, weekly "on the job training" to the colleagues of the Obstetrical Department. Taken together, these educational initiatives could explain the decreased mortality rate due to asphyxia. We consider to continue supporting this program on resuscitative maneuvers because previous work showed a decay of staff performance over time [22].

Nevertheless, the number of patients admitted for asphyxia (492 vs 641, $p<0.01$ ) increased after CUAMM intervention. These findings could have different explanations: the effect of educational intervention on assigning Apgar score, the increased number of admissions of patients suffered from milder asphyxia and the improved management of these patients during hospital stays.

Despite the training on hand wash, the creation of protocols on neonatal sepsis's treatment of and antibiotics supply, the mortality rate for sepsis did not decrease as expected. In a hospital survey conducted in the first trimester of 2014 , only $78 \%$ of the NICU staff washed the hands properly. This number was even lower in the Obstetrical Department (about 30\%) [23]. 
Our program included the provision of a point-of-care reader for C-Reactive Protein (CRP). However, we realized that it was used rarely, due to the lack of confidence and trust of the instrument by the local staff. However, when a clinical diagnosis of sepsis was suspected and CRP was negative, the antibiotic treatment was started. Serial CRP measurements were not used for interrupting antibiotic treatment.

Our study has some limitations due to the retrospective design itself. Misclassification can be occurred particularly in defining LBW infants and prematurity and in attributing causes of death because most of the diagnoses were clinically based, without any laboratory or instrumental support.

Finally, although, our initiatives, taken together, were able to reduce mortality rate in this referral low resource NICU, it was not possible to exactly determine the role of each intervention on the final positive outcome.

Future Quality Improvement interventions for reducing mortality and morbidity rate will focus on implementing the actual program and progressively introducing new strategies such as the disinfection of the umbilical cord with chlorhexidine, introduction of antenatal corticosteroid prophylaxis (actually not provided in Beira) and education on the use of devices for non-invasive respiratory support. Monthly meetings on maternal and neonatal deaths between Obstetrical and Pediatric staff are routinely held at $\mathrm{CBH}$. They are based on the revision of the medical reports, without a well-structured evaluation tool. Specific instruments to guide these discussions and provide useful feedbacks to the staff should be recommended.

As during the study period there was neither a better electricity supplies nor a increasing of the healthcare providers'salaries, these aspects should be taken into account in the future.

The sustainability of this project was initially due to the collaboration between CUAMM and the CBH. Local administration has been planning to financially support these Quality Improvements at the end of the CUAMM project in 2017, suggesting that the collaboration with local political, administrative and clinical staff is a key point to maintain the changes over time.

\section{Conclusions}

Our study shows that a Quality Improvement intervention based on infrastructure, equipment and clinical protocols was associated to a reduction of neonatal mortality rate, especially that due to prematurity and asphyxia in a lowresource setting. Randomized controlled trials are needed to evaluate the real impact of this intervention, excluding confounding factors.

\section{Abbreviations}

CBH: Central Beira Hospital; CRP: C-Reactive Protein; KMC: Kangaroo Mother Care; LBW: low birth weight; NICU: Neonatal Intensive Care Unit; VLBW: very low birth weight

\section{Acknowledgements}

We are very grateful to all the Obstetrical and NICU's staff of the Beira Central Hospital for their work and to all the local CUAMM's staff for their support during this study.

\section{Funding}

None.

Availability of data and materials

The datasets used and analysed during the current study can be available from the corresponding author on reasonable request.

\section{Authors' contributions}

$\mathrm{PL}, \mathrm{AS}$ and MEC conceived and designed the study. MEC undertook the data collection. MD provided advice on study design and statistical analysis. MEC analysed the data. DT and MEC drafted the manuscript with significant contributions from DP, WMO, GP and LDD. All authors approved the final version of the manuscript.

\section{Competing interests}

None.

\section{Consent for publication}

Not applicable.

\section{Ethics approval and consent to participate}

Ethical approval to conduct the study was obtained from the National Research Ethics Comitee of Mozambique. Patient's consent to participate was not required due to the retrospective design of the study conducted.

\section{Author details}

${ }^{1}$ Doctors with Africa CUAMM, Padova, Italy. ${ }^{2}$ Central Hospital of Beira, Beira, Mozambique. ${ }^{3}$ Department of Woman's and Child's Health, University of Padova, Via Giustiniani 3, Padova 35128, Italy.

Received: 11 February 2016 Accepted: 17 November 2016

Published online: 22 November 2016

\section{References}

1. Unicef. Levels \& Trends in Child Mortality. Report 2014. http://www.unicef. org/media/files/Levels_and_Trends_in_Child_Mortality_2014.pdf. Accessed Feb 2016.

2. Lawn JE, et al. Neonatal Survival Steering Team. 4 million neonatal deaths: when? Where? Why? Lancet. 2005;365:891.

3. World Health Organization and UNICEF. Countdown to 2015 decade report (2000-2010): tacking stock of maternal, newborn and child survival. 2010. Accessed 01 Feb 2016

4. World Health Organization. Health-related Millennium Development Goals. World Health Statistics. (2014). http://www.who.int/topics/millennium_ development_goals/en/. Accessed 1 Jan 2016.

5. Ministério da Saúde da República de Moçambique. "No Title," 2014.

6. Doctors with Africa CUAMM. http://www.mediciconlafrica.org/en/what-we-do/ in-africa. Accessed 1 Feb 2016.

7. Donabedian A. The quality of care: how can it be assessed? JAMA. 1988;260: 1743-8.

8. Sarnat $\mathrm{HB}$, et al. Neonatal encephalopathy following fetal distress. A clinical and electroencephalographic study. Arch Neurol. 1976;33:696-705.

9. Gilbert $\mathrm{EH}$, et al. Chart reviews in emergency medicine research: Where are the methods? Ann Emerg Med. 1996;27:305-8.

10. Department of Reproductive Health and Research. Kangaroo mother care: a practical guide. World Health Organization, Geneva: http://apps.who.int/ iris/bitstream/10665/42587/1/9241590351.pdf. Accessed Feb 2016

11. Conde-Agudelo A. et al. Kangaroo mother care to reduce morbidity and mortality in low birthweight infants. Cochrane Database Syst Rev. 2014; doi:10.1002/14651858.CD002771.

12. Lawn JE, et al. Kangaroo mother care to prevent neonatal deaths due to preterm birth complications. Int J Epidemiol. 2010;39 Suppl 1:1144-154. doi:10.1093/ije/dyq03.

13. Boundy EO, et al. Kangaroo Mother Care and Neonatal Outcomes: A Metaanalysis. Pediatrics. 2016;137:1-16. 
14. Carlo WA, et al. Newborn-care training and perinatal mortality in developing countries. N Engl J Med. 2010;362:614-23.

15. Perlman JM, et al. Neonatal Resuscitation Chapter Collaborators. Part 7: Neonatal Resuscitation: 2015 International Consensus on Cardiopulmonary Resuscitation and Emergency Cardiovascular Care Science With Treatment Recommendations. Circulation. 2015;132:S204-41.

16. Lozano R, et al. Progress towards Millennium Development Goals 4 and 5 on maternal and child mortality: an updated systematic analysis. Lancet. 2011;1139-65.

17. Newton $\mathrm{O}$, et al. Newborn resuscitation: defining best practice for low-income settings. Trans R Soc Trop Med Hyg. 2006;899-908.

18. Kim YM, et al. Assessing the capacity for newborn resuscitation and factors associated with providers' knowledge and skills: a cross-sectional study in Afghanistan. BMC Pediatr. 2013;140.

19. Sibley $\mathrm{L}$, et al. Traditional birth attendant training for improving health behaviours and pregnancy outcomes. Cochrane Database Syst Rev. 2012;8, CD005460. doi:10.1002/14651858.CD005460.

20. Singhal $\mathrm{N}$, et al. Helping Babies Breathe: global neonatal resuscitation program development and formative educational evaluation. Resuscitation. 2012;83:90-6

21. Trevisanuto D, et al. Effect of a Neonatal Resuscitation Course on Healthcare Providers' Performances Assessed by Video Recording in a Low-Resource Setting. Plos One. 2015;11:10(12).

22. Mosley C, et al. A longitudinal cohort study to investigate the retention of knowledge and skills following attendance on the Newborn Life support course. Arch Dis Child. 2013;98:582-6.

23. Ministerio da Saude (MISAU), Instituto Nacional de Estatística (INE) e ICF International (ICFI). Moçambique Inquérito Demográfico e de Saúde 2011. Calverton, Maryland, USA: MISAU, INE e ICFI. 2011.

\section{Submit your next manuscript to BioMed Central and we will help you at every step:}

- We accept pre-submission inquiries

- Our selector tool helps you to find the most relevant journal

- We provide round the clock customer support

- Convenient online submission

- Thorough peer review

- Inclusion in PubMed and all major indexing services

- Maximum visibility for your research

Submit your manuscript at www.biomedcentral.com/submit 